\title{
A CIDADE E O PATRIMÔNIO PÓS-INDUSTRIAL: POTENCIALIDADES ACERCA DA USINA DO QUEIMADO EM CAMPOS DOS GOYTACAZES/RJ
}

\author{
THE CITY AND POST-INDUSTRIAL PATRIMONY: POTENTIALITIES ABOUT THE \\ USINA DO QUEIMADO IN CAMPOS DOS GOYTACAZES/RJ
}

\author{
Larissa Miranda Sá \\ Fagner de Oliveira das Neves
}

\section{Resumo}

Com o intuito de analisar as possibilidades no âmbito político-legal e identificar os potenciais acerca do espaço, este trabalho se concentra no patrimônio industrial da cidade de Campos dos Goytacazes, apresentando como objeto de estudo o complexo da antiga edificação e as áreas livres do entorno da Usina do Queimado. Suas instalações contemplam grandes espaços, que se encontram sem uso em uma malha urbana consolidada. Situada na entrada da cidade, possui grande visibilidade, principalmente para o mercado imobiliário, fazendo desse espaço um local de conflitos socioeconômicos. Assim, baseando-se na legislação específica, foram apresentados os entraves acerca do objeto de estudo e verificadas as possibilidades diante desse panorama, considerando-se instrumentos de política urbana. Por fim, concluiu-se que a legislação não possui especificidades capazes de determinar intervenções que garantam a função social da propriedade urbana. Nesse sentido, dentre os instrumentos, àquele que pode ser empregado ao caso é o Direito de Preempção.

Palavras-chave: Patrimônio Industrial. Legislação. Política Urbana. Função Social.

\section{ABSTRACT}

With the purpose of analyzing possibilities in the political-legal sphere and identifying the potential about space, this work focuses on the industrial heritage of the city of Campos dos Goytacazes, presenting as object of study the complex of the old building and the free areas in the immediate surroundings of Usina do Queimado. Its facilities contemplate large spaces, which are unused in a consolidated urban network. Located at the entrance of the city, it has a great visibility, mainly for the real estate market making this space a place of socioeconomic conflicts. Thus, based on the specific legislation, the obstacles were presented about the object of study and verified the possibilities in view of this panorama, considering urban policy instruments. Finally, it was concluded that the legislation does not have specificities capable of determining interventions that guarantee the social function of urban property. In this sense, among the instruments, the one that can be used to the case is the Right of Preemption.

Keywords: Industrial Patrimony. Legislation. Urban Politics. Social Function.. 


\section{INTRODUÇÃO}

Este trabalho analisa as possibilidades políticas-legais e as potencialidades da herança pós-industrial na cidade de Campos dos Goytacazes, estado do Rio de Janeiro. Apresenta como objeto de estudo o patrimônio industrial da Usina do Queimado, uma vez que ela está situada em uma parte da mancha urbana extremamente consolidada.

Para Mesquita e Teixeira (2010), o termo Patrimônio Industrial nos remete a grandes estruturas, com forte valor arquitetônico, antigos maquinários, espaços ociosos, que foram assimilados (ou destruídos) pela modernidade.

Desde o princípio, de acordo com Pinto (1995), Campos dos Goytacazes foi a terra feita para o açúcar. Um conjunto favorável de fatores de natureza climática e um excelente panorama fisiográfico facilitaram e induziram o crescimento de um povoamento às margens do Rio Paraíba do Sul. A cidade se transformou ao longo de mais de três séculos e meio em um vigoroso centro de progresso e desenvolvimento.

\section{Para o referido autor:}

Essa evolução foi iminente no setor usineiro. Na cidade havia grandes usinas de açúcar e álcool funcionando a todo vapor, contribuindo para um crescimento urbano acelerado. Campos foi a única cidade no contexto brasileiro construída exclusivamente pela economia açucareira e se manteve fiel às suas origens, refletindo a atividade de sua monocultura no comportamento de sua sociedade urbana e rural (PINTO, 1995, p. 21).

Nesse período, algumas usinas foram destaque no cenário campista pela sua produção. No topo da lista estavam as usinas: N. Dores, S. Antônio, N. S. Desterro, S. Cruz e Queimado, segundo a tabela global de produção de 1917, mencionada no livro 0 Ciclo do Açúcar em Campos, do autor Jorge Renato Pereira Pinto.

Devido à grande produção e visibilidade, além de promover o desenvolvimento da cidade, esse ritmo rapidamente também im- pulsionou o aumento da riqueza dos proprietários das usinas, que por sua vez se tornaram donos de glebas cada vez maiores dentro da cidade.

Nesse contexto, onde o desenvolvimento se dava através da produção das usinas, em que os usineiros eram detentores de uma grande quantidade de terras, a lógica de dominação e de territorialização se instalava. Segundo relato trazido na obra de Carvalho (1974 apud GANTOS; SOUZA, 2006, p. 5), "meu ideal era ser usineiro, viver no último andar de 300 mil sacos de açúcar".

O pensamento do usineiro refletia o estilo de vida que se desejava naquele período, configurando uma dominação e territorialização do espaço urbano cada vez maior. Cada usina era uma ilha dentro do município, com hábitos e tradições próprias e em volta de cada uma girava o trabalho, a família, o progresso, o futuro (PINTO, 1995).

Após a decadência do setor sucroalcooleiro, as terras pertencentes aos usineiros e posteriormente às suas famílias permanecem como grandes espaços livres de grande potencial, não apenas pelo tamanho ou arquitetura das antigas edificações, mas também pela memória de uma sociedade.

Todavia, atualmente, são os entraves acerca dessas glebas que vêm gerando impedimentos de âmbito legal que interferem diretamente no desenvolvimento e consequentemente em seu uso.

Este trabalho tem como objetivo identificar as potencialidades de uso e possibilidades no âmbito político-legal do objeto de estudo, levando em consideração seus aspectos históricos, culturais e paisagísticos resultantes do período industrial sucroalcooleiro. Para alcançar este objetivo, faz-se necessário apresentar o contexto histórico e cultural, apresentar os entraves político-legais e econômicos atuais, verificar as possibilidades diante do panorama político-legal relacionadas à área e identificar as potencialidades de uso levando em conta a edificação existente e os espaços livres do entorno imediato.

Ademais, sua relevância se dá primeiramente por se tratar de um período da história da sociedade campista de grande desenvol- 


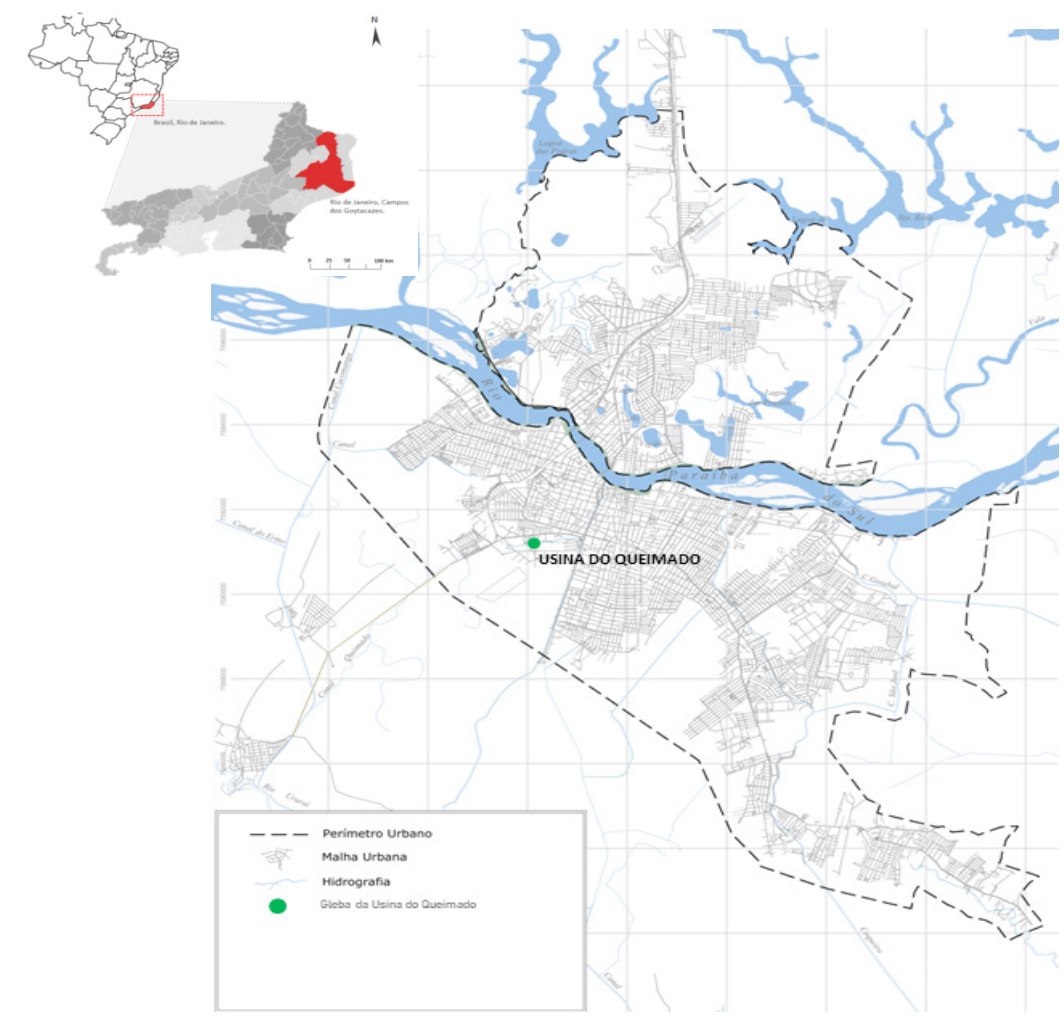

Figura 1 - Mapa esquemático de localização do Município de Campos dos Goytacazes no estado do Rio de Janeiro e do objeto de estudo, Usina do Queimado.

Fonte: Produzido por Larissa Miranda Sá (2018), com base no anexo Mapa 1 - Sede da Lei n 7.973 - Perímetros Urbanos do Município, 2008.

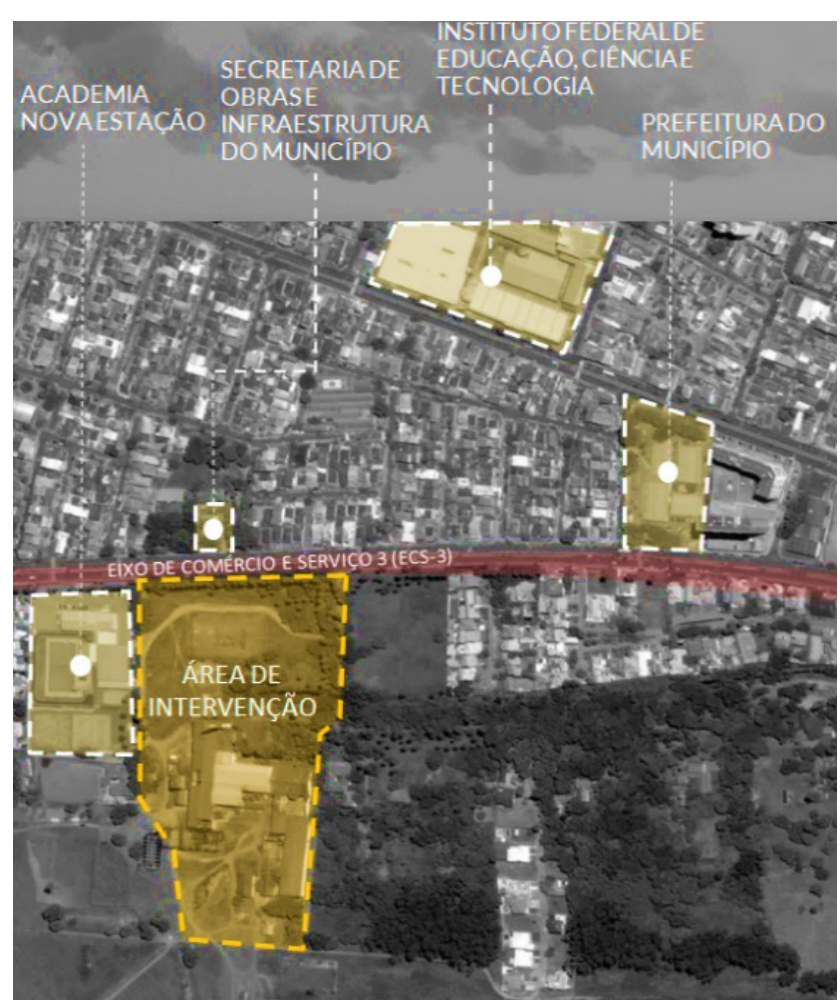

Figura 2 - Esquema de localização da Usina do Queimado e Avenida Dr. Nilo Peçanha (Eixo de Comércio e Serviço 3 - ECS-3).

Fonte: Produzido por Larissa Miranda Sá (2018), com base em imagem extraída do Google Earth Pro. vimento e transformação urbana, que deixou um vasto repertório de edificações industriais e espaços livres. Em segundo lugar, porque a Usina do Queimado está localizada na entrada da cidade, atraindo a atenção do mercado imobiliário e de investidores. Outrossim, por estar situada em uma avenida de extrema importância (Avenida Dr. Nilo Peçanha), que é também um Eixo de Comércio e Serviços 3 (ECS-3), em uma gleba onde o preço do metro quadrado é um dos mais altos da cidade.

No mapa do município de Campos dos Goytacazes, que pode ser visualizado na Figura 1, está localizada a Usina do Queimado. É possível observar que o objeto de estudo está dentro do perímetro urbano (linha tracejada): 
Ao observar a malha urbana, na qual a usina está inserida, é possível observar que se trata de um espaço urbano bastante consolidado e que é uma problemática a subutilização da gleba que compreende a antiga edificação e seus espaços livres. Além disso, há um grande potencial arquitetônico e paisagístico.

O procedimento metodológico deste trabalho concentra-se: (a) na revisão bibliográfica sobre a cidade de Campos dos Goytacazes, período sucroalcooleiro até a atualidade; (b) no objeto de estudo: a Usina do Queimado; e (c) Análise documental.

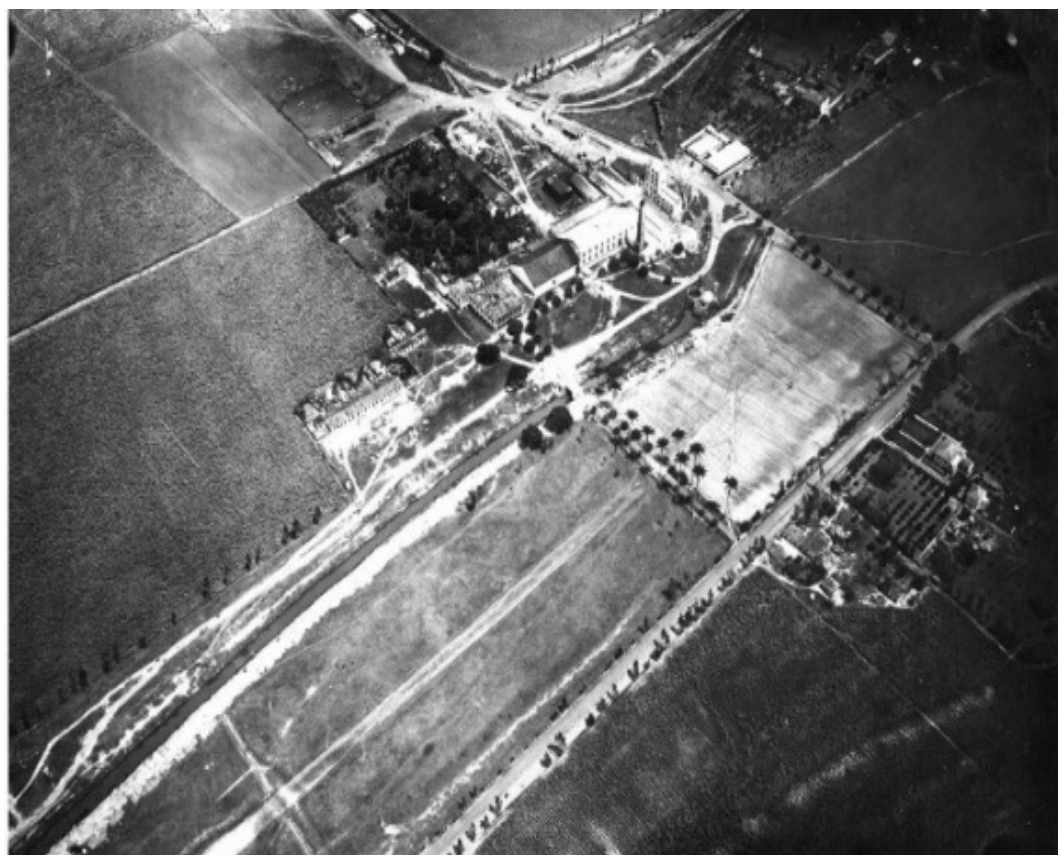

Figura 3 - Vista aérea da Usina do Queimado, 1880. Destacada em vermelho a Avenida Dr. Nilo Peçanha.

Foto: Arquivo pessoal de Eduardo Linhares, concedida em 2016.

\section{USINA DO QUEIMADO: DA História à CONTEMPORANEIDAde}

A história da Usina do Queimado teve início em 1880. Neste ano, Campos dos Goytacazes já havia sido elevada à categoria de cidade e as transformações urbanas foram acontecendo paulatinamente ao longo de décadas.

É possível observar na Figura 3 como era o entorno da usina naquela época, a Avenida Dr. Nilo Peçanha ainda era de terra e ao redor da usina havia espaço para o plantio da principal matéria -prima, a cana-de-açúcar.

Naquela época, segundo entrevista com Eduardo Linhares (informação verbal) ${ }^{1}$, um dos herdeiros da usina:

a relação que existia entre proprietários e trabalhadores era de respeito e altruísmo, havia incentivos por parte dos proprietários para participação em diferentes festivais. Nas terras da usina os trabalhadores encontravam toda estrutura necessária para a vida, eram estruturas de armazéns, enfermarias e até escola, pois ir ao centro significava fazer uma pequena viajem.

Em uma breve digressão à luz de Godelier (2001 apud GANTOS; SOUZA, 2006, p. 8), "o dom pode ser, ao mesmo tempo ou sucessivamente, ato de generosidade ou ato de violência, mas nesse caso de uma violência disfarçada de gesto desinteressado, pois se exerce por meio e sob a forma de uma partilha".

Assim, propõe-se uma reflexão acerca da relação entre os usineiros e trabalhadores, uma vez que, na maioria das vezes, essas relações tinham características que contradizem o relato de Linhares. A história acerca deste período aponta para uma situação de trabalho exploratória. Os usineiros exerciam sua "força" controlando meios de produção, detendo o poder econômico, social e político local, conforme se extrai do seguinte trecho:

1 Entrevista cedida a Larissa Miranda Sá em Campos dos Goytacazes, em 28 de abril de 2016 
O poder econômico descrito funcionava articulado a um modo de dominação simbólico, peculiar que esteve vinculado às formas de reciprocidade e dispositivos de controle social próprios de um modo agrário patriarcal, que foram hibridizados e adaptados a formas de dominação como a dádiva e o coronelismo, dispositivos de poder de base autoritária e clientelística que funcionaram em um contexto de relações de produção de base capitalista (GANTOS E SOUZA, 2006, p. 6).

Ao longo dos anos, a usina passou por uma grande modernização e adquiriu maquinários da Inglaterra e suas três locomotivas. Na cidade como um todo, houve uma rápida modernização - resultado da visibilidade que a produção de açúcar e álcool das usinas trouxe para a região. Vemos na Figuras 4 que a cidade recebeu visitas ilustres, como o presidente Getúlio Vargas e sua comitiva, que estiveram na usina a fim de acompanhar o processo

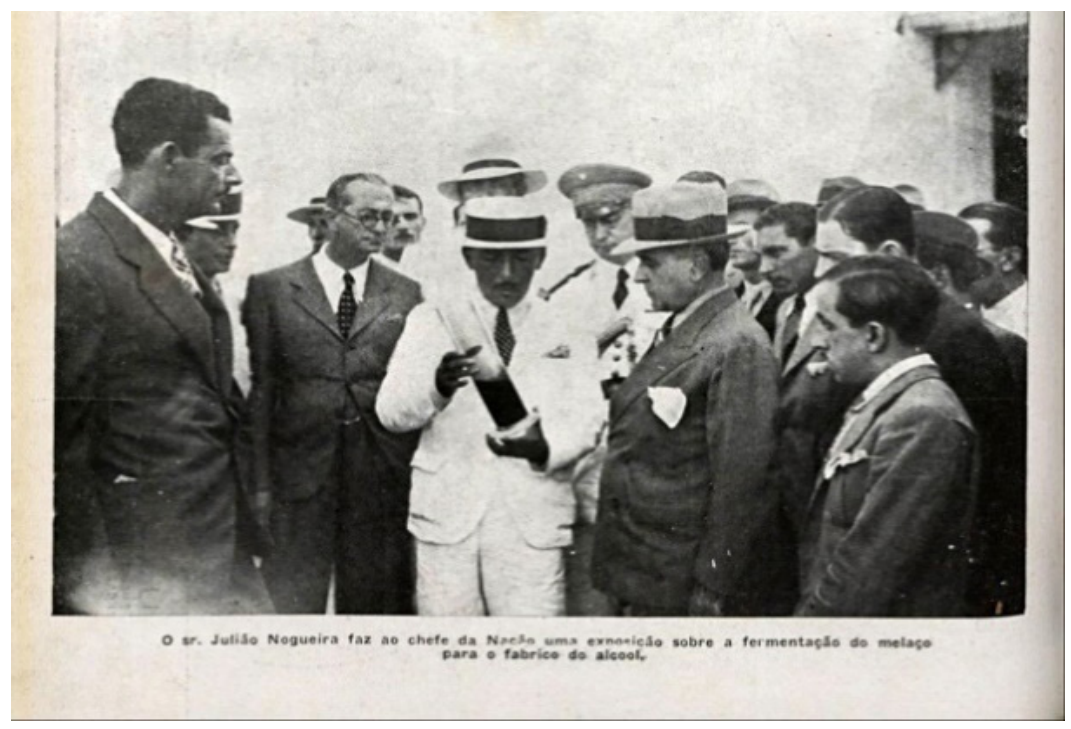

Figura 4 - Julião Nogueira e Getúlio Vargas, uma exposição do melaço para o fabrico do álcool.

Fonte: Arquivo pessoal de Eduardo Linhares, 1944. de crescimento e modernização, como é visto na Figura 5, que ela e a cidade de Campos dos Goytacazes vivenciavam.

É fato que o papel das usinas no desenvolvimento da cidade de Campos dos Goytacazes foi preponderante. Trouxe riqueza, prosperidade e tornou a cidade conhecida em grandes centros urbanos, como por exemplo, Rio de Janeiro.

Conforme Pinto (1995, p. 146),

Para a agroindústria, os surgimentos de fases boas e ruins sempre se revezaram sem separativismos de natureza política ou social. Não foi a República ou a mudança de século ou mesmo o desaparecimento da escravatura que criariam etapas diferentes. Para as fábricas açucareiras tudo foi um continuar de lutas, de grandezas, de misérias e de crises. Aqui e ali, mudavam-se os donos. Lá e acolá, fechavam-se fábrica. Para muitos ex-propie-

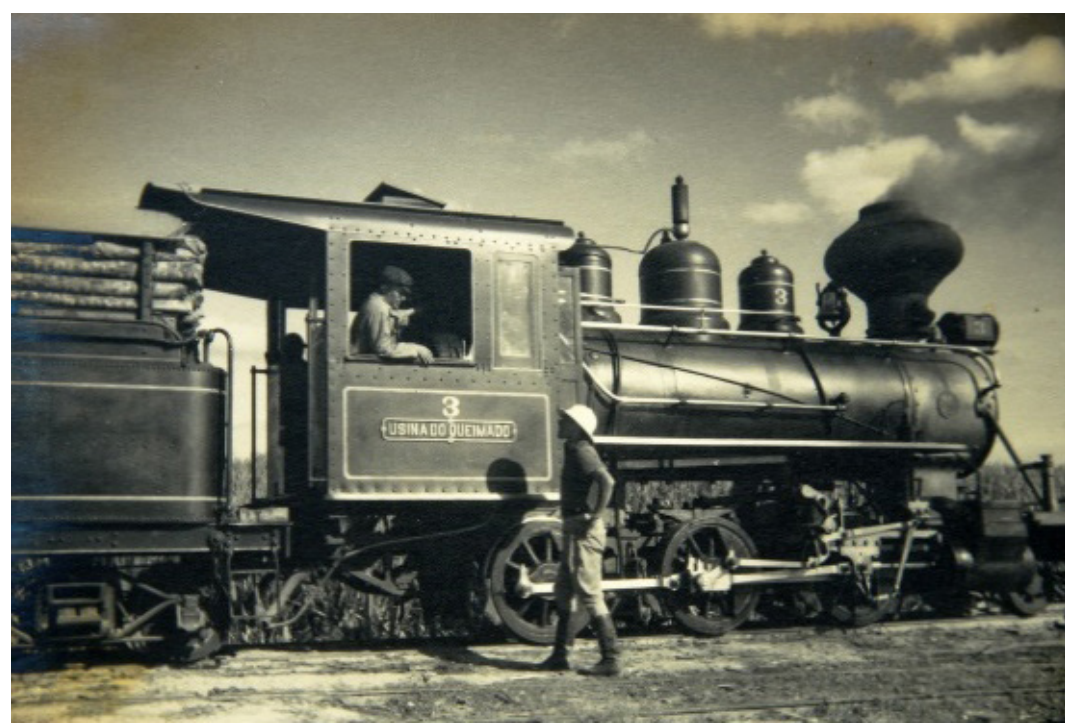

Figura 5 - Locomotiva $\mathrm{n}^{\circ} 3$ da Usina do Queimado. Fonte: Arquivo pessoal de Eduardo Linhares, 1945. 
tários, modificava-se o destino, o caminhar da vida, com o desaparecimento de momentos eventuais de glórias efêmeras, elucida.

Com terras a perder de vista, o espaço livre que compõe todo entorno imediato da usina é dotado de uma grande área verde remanescente do seu período de funcionamento. Nesta área encontram-se diversas espécies de árvores e arbustos, que desenham a paisagem campista há décadas. Contudo, é possível afirmar que os resquícios dos tempos áureos (virada do século XIX para o século $X X$ ) de produção sucroalcooleira são elementos constituintes da paisagem campista, não se restringindo à zona rural (MESQUITA; TEIXEIRA, 2010).

A aleia de Palmeiras Imperiais (Roystonea Oleracea) e o Canal de Queimados, que antigamente se conectava ao Canal Campos-Macaé, são elementos que também caracterizam o local, juntamente com a antiga edificação industrial. Ainda, ao tratar da paisagem, outra característica marcante no cenário campista são as chami-

Atualmente se encontram na usina as caldeiras e a moenda de cana inglesa, equipamentos remanescentes da época em que ela funcionava. Maquinários gigantes que mais se parecem esculturas em meio a uma arquitetura extremamente característica trazem à tona a memória de um período de extremas mudanças.

A sociedade campista experimentou uma enorme transformação urbana em um curto período de tempo. Como mostra a história, grande parte desta transformação está relacionada aos usineiros, pois detinham uma enorme quantidade de terra e prestígio entre políticos e famílias mais abastadas. Essa forma de poder sobre a cidade mostra claramente que a riqueza se concentrava nas mãos de poucos, uma vez que grande parte do território urbano era de propriedade de determinada usina.

Conforme Gantos e Souza (2006), neste contexto, o usineiro disponha do poder absoluto de decidir onde o excedente produzido por toda a vila, comunidade ou até mesmo o município seria alocado. Assim, tomando o território como um espaço definido e delimitado por e a partir de relações de poder podemos ter uma

ideia da responsabilidade que o setor dos usineiros teve na construção de uma particular noção de territorialidade.

\section{Panorama Político-Legal e ECONOMMICO ATUAL}

Sob o contexto político-legal, o principal entrave observado acerca do objeto de estudo é de caráter jurídico e está ligado às glebas da usina. De acordo com as pesquisas levantadas para este trabalho, é possível afirmar que a Usina do Queimado ainda detém uma significativa quantidade de glebas dentro da cidade. Todavia, os litígios decorrentes de diferentes ações impedem que sejam comercializadas e que novos usos sejam estabelecidos, uma vez que necessitariam altos investimentos.

Este trabalho analisa a gleba do entorno imediato da usina. Portanto, há de se notar que se trata de um grande espaço livre em um contexto extremamente consolidado que não possui uso significativo, isto porque há também a promoção de eventos esporádicos onde os proprietários alugam parte do espaço.

Outro fator preponderante, quando observada como sendo parte do patrimônio industrial da cidade, quando aparece no Plano Diretor do Município de Campos dos Goytacazes (CAMPOS..., 2007), de forma direta na Subseção III - Das Áreas de Preservação do Patrimônio Cultural (art. 228, inciso IV, da Lei n 7.972 , de 31 de março de 2008), Institucionais e Outros - m) Conjunto industrial da Usina do Queimado com aléia de palmeiras e indiretamente nos art. 89 e 137, que tratam respectivamente da valorização do patrimônio natural e cultural e das áreas de preservação natural e cultural.

Além de constar também na Resolução $n^{\circ}$ 005/2013 (CAMPOS..., 2013), publicada no Diário Oficial do Município de 12 de setembro de 2013, sob orientação do Conselho de Preservação do Patrimônio Municipal (COPPAM), que resolve:

art. $1^{\circ}$ - Ficam tombadas as edificações e os imóveis a seguir citados e identificados no processo aprovado pelos demais conselheiros, pelo seu valor histórico, ar- 
quitetônico e cultural para o município.

[...]

3: Casa Sede da Usina do Queimado, Usina do Queimado.

Vale ressaltar que o complexo industrial da Usina do Queimado não é tombado, mas é passível de preservação por ser considerado parte do patrimônio cultural da cidade.

Considerando os entraves de caráter econômico, o entorno experimenta uma dinâmica de capital que é extremamente cadenciada pelo mercado imobiliário, que por sua vez propõe valores altamente rentáveis, possíveis apenas para uma classe dominante que reconfigura o espaço com novos usos.

Ao observarmos a questão econômica, Marx (1967 apud HARVEY, 2005), argumenta que a renda da terra é elemento essencial no processo de produção social. Na verdade, é a base ou pré-condição desse processo.

O objeto de estudo, mesmo quando visto como paisagem residual é também parte desta dinâmica, pois o seu valor sob a ótica do mercado imobiliário não está ligado ao fato de ser um patrimônio industrial ou uma memória da sociedade e sim pelo seu tamanho e localização na mancha urbana.

Segundo Mesquita e Teixeira, (2010, p. 11):

ainda assim, esta nova forma de apropriação é indissociável da paisagem residual. Esta nova materialidade espacial está em permanente diálogo com as estruturas das antigas usinas, uma vez que os novos usos acontecem em seu entorno. Os antigos galpões com seu maquinário, as chaminés, e outras estruturas permanecem na paisagem permitindo a análise e a reconstrução do passado.

Para Villaça (2001 apud FREITAS, 2011), a terra urbana tem valor como qualquer mercadoria, pois o trabalho humano e as relações sociais desenvolvem a localização, fundamental na determinação do preço do lote com base no princípio da terra. Conforme observa o autor:
Há consenso atualmente de que o espaço urbano é produzido [...] pelo trabalho social despendido na produção de algo socialmente útil. Logo, esse trabalho possui um valor. Uma pergunta fundamental que poucos se fazem: qual é o produto deste trabalho? Há aí dois valores a se considerar. O primeiro é o dos produtos em si [...]. O outro é o valor produzido pela aglomeração. Esse valor é dado pela localização (das formas espaciais). [...] A localização se apresenta assim como um valor de uso da terra que, no mercado, se traduz em preço da terra.

No entendimento de Maricato (2003), mercado para poucos é uma das características de um capitalismo que combina relações modernas de produção com expedientes de subsistência.

A afirmação acima corrobora com o aspecto localização $\square$ fundos públicos, uma vez que grandes investimentos são feitos em áreas onde há interesse imobiliário e as classes com maior poder aquisitivo se concentram. Neste sentido, entende-se que a política urbana com suas medidas modernizantes de produção do espaço urbano possui caráter excludente, que, aliás, é bastante presente no objeto de estudo, uma vez que está localizada em uma área privilegiada.

\section{Possibilidades Sob o Viés Político-Legal}

No que tange aos instrumentos políticos-legais relacionados ao objeto de estudo, é possível apontar pelo menos três principais legislações que indicam formas para atribuir usos ao espaço.

Inicialmente, destaca-se a Lei Orgânica do Município de Campos dos Goytacazes (CAMPOS..., 2014), que em seu art. $4^{\circ}$, inciso XIII, dispõe: "promover o adequado ordenamento territorial, mediante planejamento e controle do uso, do parcelamento e da ocupação do solo urbano, e estabelecer normas de edificações"; e no art. $4^{\circ}$, inciso XXVI, prevê "a proteção e a conservação do patrimônio histórico, artístico e cultural (material e imaterial) local, observadas à legislação e a ação fiscalizadora federal e estadual". 
Em segundo lugar, o Plano Diretor do Município de Campos dos Goytacazes (CAMPOS..., 2007), que no art. 89 prevê:

Art. 89. Para a valorização do patrimônio natural e cultural serão executadas as seguintes ações e medidas de gerenciamento:

I - Revitalizar espaços culturais - como o Centro Histórico, o Horto, os casarões e usinas, parques, jardins e praças - potencializando seus usos, para o desenvolvimento de projetos culturais e áreas de lazer.

Outro dispositivo legal utilizado foi a Lei de Uso e Ocupação do Solo Urbano (CAMPOS..., 2008), que, conforme indicado no Quadro $\mathrm{n}^{\circ} 6$ - Índices de Intensidade de Ocupação, no Anexo II da Lei $n^{\circ}$ 7.974, de 31 de março de 2008, em seu art. 89 dispõe: "As áreas urbanas que apresentam potencial para a Outorga Onerosa do Direito de Construir, segundo as diretrizes estabelecidas na Lei do Plano Diretor estão incluídas nas Zonas Residenciais ZR-3 e
ZR-4 e nos Eixos de Comércio e Serviços ECS-2 e ECS-3".
É importante ressaltar que as legislações mencionadas acima possibilitam viabilizar novos usos para esses antigos complexos industriais. Porém, as menções existentes necessitam de especificações para que sejam de fato efetivadas. Devido à ausência destas especificações os instrumentos de política urbana ainda estão "aquém" do seu conceito e funcionamento para a cidade.

As possibilidades são observadas sob os instrumentos de política urbana regulamentados pelo Estatuto da Cidade (BRASIL, 2001), que incidem sobre o zoneamento do objeto de estudo. Nesta ótica, são apontadas pelo menos três possibilidades acerca do espaço.

Todavia, o primeiro ponto importante que deve ser observado e que compreende não só os instrumentos citados neste trabalho, mas todos que estão presentes no Estatuto da Cidade é a função social que estes instrumentos foram criados para cumprir. Esta função tem o intuito de promover um adequado aproveitamento do solo urbano, a fim de que todos tenham acesso à cidade e aos

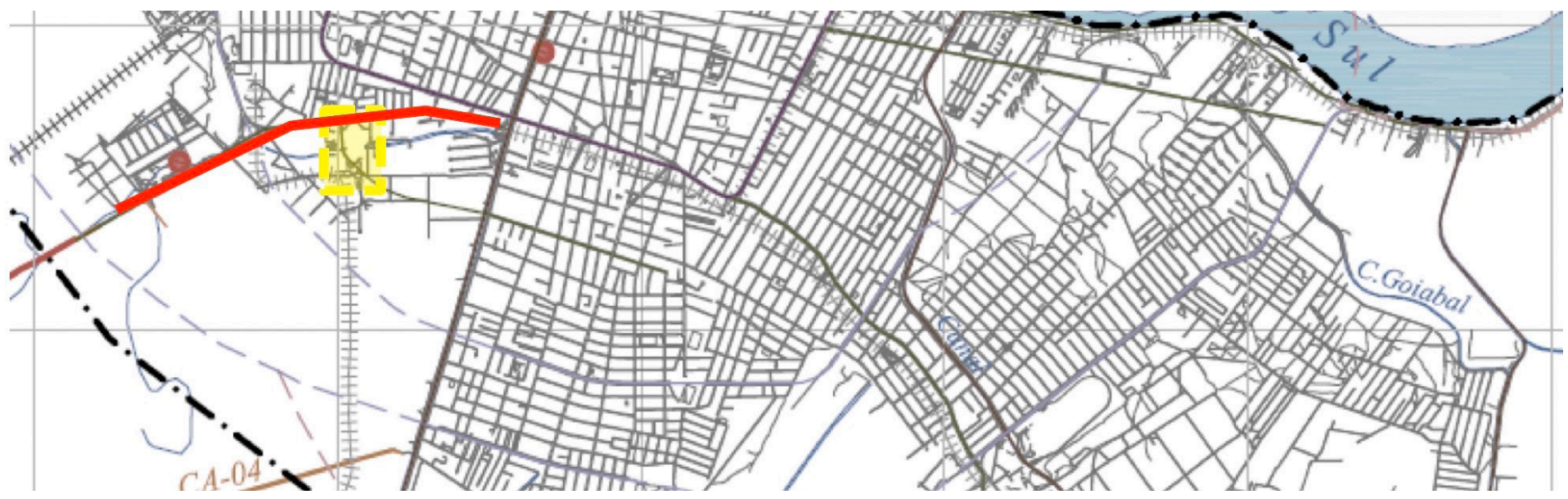

Figura 6 - Mapa de Mobilidade Urbana. Em vermelho ECS-3, em amarelo ZR -2, Usina do Queimado. Fonte: Plano Diretor. Lei n 7. 972, 31 de março de 2008. 
recursos urbanísticos por ela oferecidos, conforme observa Santin e Marangon (2008).

Ainda, segundo as autoras, neste sentido, no Estatuto da Cidade, as diretrizes gerais e os instrumentos de política urbana compõem um conjunto de normas que vão permitir um racional aproveitamento do solo urbano, planejando a vida em comunidade, promovendo à propriedade sua função social, objetivando melhorar o ambiente urbano em todas as suas dimensões. Por tais razões a aplicação destes instrumentos de forma homogênea dentro no território urbano é tão importante.

Por outro lado, o que é observado é que estes instrumentos costumam ser aplicados em locais já favorecidos, fato que promove ainda mais desigualdade socioespacial no território urbano. A ausência de uma regulamentação específica para cada instrumento também corrobora com essa situação, pois valida a oportunidade de serem utilizados fora do seu conceito real, aqueles, citados anteriormente.

Conforme apresentado na Figura 6, a Usina do Queimado está situada em um ECS-3 e na Zona Residencial -2 (ZR-2). É interessante observar o primeiro instrumento de política urbana a ser discutido para o espaço em questão, Direito de Preempção (art. 25, Estatuto da Cidade).

Entre as possibilidades político-legais relacionadas ao espaço em questão, o Direito de Preempção, conforme art. 278 do Plano Diretor, o poder público pode direcionar e fomentar potenciais usos para a área. Vale ressaltar que o próprio Estatuto da Cidade em seu art. 25 , $\S 1^{\circ}$, solicita lei municipal baseada no Plano Diretor para concretizar o Direito de Preempção.

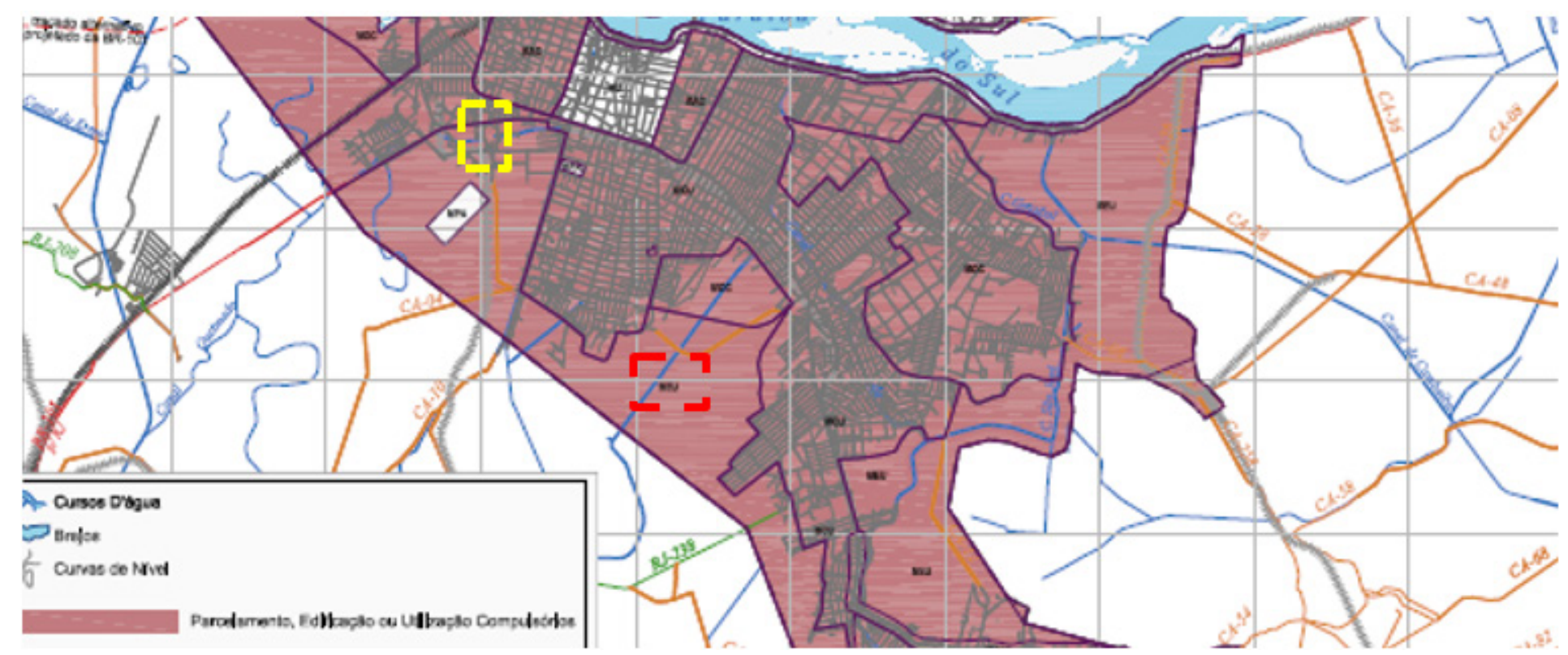

Figura 7 - Mapa de Parcelamento, Edificação e Utilização Compulsórios. Em amarelo a área da Usina do Queimado. Em vermelho, Macrozona de Expansão Urbana.

Fonte: Extraído do Plano Diretor. Lei n 7. 972, 31 de março de 2008. 
Nesse instrumento, o poder público municipal tem a preferência para a aquisição de imóvel urbano objeto de alienação onerosa entre particulares. Conforme a especificação do Plano Diretor, esse instrumento incide sobre a Macrozona de Expansão Urbana (MEU), zona em que está localizada a gleba da Usina do Queimado. Suas localizações podem ser vistas na Figura 7.

Em posse do poder público esse espaço urbano ainda sofre influência do mercado imobiliário, porém as intenções de uso ganham outro significado que primeiramente respeitariam a condição enquanto patrimônio industrial da cidade e espaços livres, dotados de áreas verdes, depois pelo seu potencial como espaço de integração de diferentes atividades de cunho ambiental, cultural e comercial.

Outro mecanismo que incide sobre a MEU, previsto no art. 35 do Plano Diretor para o objeto de estudo, é a Transferência do Direito de Construir. Nele, o poder público pode autorizar ao proprietário do imóvel o direito de construir em outro espaço ou alienar mediante escritura pública, uma vez que o seu imóvel seja considerado necessário para fins de implantação de equipamentos urbanos e comunitários; e preservação, quando o imóvel for considerado de interesse histórico, ambiental, paisagístico, social ou cultural ou servir a programas de regularização fundiária, urbanização de áreas ocupadas por população de baixa renda e habitação de interesse social.

Conforme coloca Saboya (2008), ao comentar sobre os instrumentos de política urbana, um exemplo são aquelas áreas que, por imposição da necessidade de preservação ambiental ou do Patrimônio Histórico, devem ter seu potencial construtivo limitado. Nesses casos, a Transferência do Direito de Construir atua como um fator de amenização da pressão imobiliária nos terrenos, diminuindo a pressão pela sua ocupação.

Nesse sentido, o poder público agindo em prol das carências da sociedade, através de um viés legal, poderia promover uma intervenção que abarcasse questões ambientais, patrimoniais e sociais. Todavia, consta no art. $35, \S 2^{\circ}$ Estatuto da Cidade, a exi- gência de lei municipal que estabeleça as condições relativas à Transferência do Direito de Construir.

Entre as possibilidades, ainda é possível citar o instrumento Parcelamento, Edificação ou Utilização Compulsórios (art. 5, do Estatuto da Cidade), como mostra a Figura 7. Este instrumento observa o solo urbano não edificado, subutilizado ou não utilizado, devendo fixar as condições e prazos para a implementação da referida obrigação por parte do proprietário do imóvel. Um fato interessante é que o Estatuto da Cidade coloca a partir deste instrumento outros instrumentos que vão complementar o processo, como o IPTU Progressivo no Tempo (art. 7) e a Desapropriação com Pagamento em Títulos (art. 8).

De modo geral, os instrumentos agem da seguinte forma: o proprietário recebe a notificação no Parcelamento, Edificação ou Utilização Compulsórios pelo Poder Executivo Municipal. Em caso do não cumprimento das condições e prazos o município pode proceder à aplicação do imposto sobre a propriedade territorial urbana (IPTU) e após cinco anos consecutivos de cobrança sem que o proprietário tenha cumprido com suas obrigações de parcelamento, edificação ou utilização, o município poderá então proceder a desapropriação do imóvel com pagamento em títulos da dívida pública. Esses títulos refletem o valor de base de cálculo do IPTU.

Em posse do imóvel, o Poder Público deve objetivar alcançar transformações urbanísticas que promovam melhorias sociais diretamente ligadas às carências da cidade, bem como sua valorização tanto arquitetônica, quanto ambiental. Entretanto, se trata de outro instrumento que o Estatuto da Cidade considera lei municipal específica.

Contudo, diante das menções acima fica compreendido que a cidade, embora esteja previsto no Estatuto da Cidade, não possui leis municipais específicas para os instrumentos de política urbana. É necessária a criação de leis para cada instrumento, que logicamente deverá estar em consonância com a legislação a qual foi citada, Estatuto da Cidade (BRASIL, 2001). 


\section{Potencialidades do Espaço}

Muito embora a dinâmica do espaço urbano tenha mudado, o horizonte ainda imprime traços do elemento industrial existente. Nesta dinâmica que é intermitente, o poder do setor imobiliário se faz extremamente presente por ser um local de grande visibilidade e consequentemente de alto interesse comercial.

Segundo Cosgrove (1998 apud MESQUITA; TEIXEIRA, 2010), é possível observar três tipos de paisagem, o da cultura dominante que revela o meio pelos quais seu poder é exercido, o das paisagens alternativas criadas por grupos não dominantes e que por isso apresenta menor visibilidade e o das paisagens residuais, cujo principal interesse está no fato de permitirem uma análise e reconstrução do passado.

Como citado anteriormente, havia uma lógica de dominação e transformação do espaço urbano, foi um processo crescente que demonstrava todo poder dos usineiros, ou seja, segundo a afirmação acima é possível dizer que se tratava de uma cultura dominante.

Neste contexto, seria correto afirmar que houve um evento de mudança da paisagem do objeto de estudo, que passou de uma cultura dominante para uma paisagem residual, tornando-se um entrave para a nova dinâmica do capital que ali se faz presente, como colocam Mesquita e Teixeira (2010) quando falam do Patrimônio Industrial de Campos dos Goytacazes.

Como parte integrante de uma paisagem residual e que possui entorno com dinâmica intensa, potencialidades também são percebidas, seja pelo elemento arquitetônico, seja pelo paisagismo bastante desenvolvido e seus espaços livres. A escolha do objeto de estudo é bastante intencional, pois revela diferentes potenciais que abarcam questões sociais, políticas e econômicas, além de sua situação, função e dinâmica no espaço urbano.

Portanto, nota-se que a importância daquele trecho, que outrora fora o principal impulsionador de desenvolvimento da cidade e que parece estar esquecido pelo fato de estar sem uso, se dá pela presença de elementos paisagísticos residuais.
Considerando que a cidade de Campos dos Goytacazes carece de estruturas de cunho cultural, há de se destacar a primeira potencialidade deste espaço, uma vez que é dotado de uma arquitetura característica e de um grande espaço livre com áreas verdes que fomentariam uma diversidade de atividades. Reconhecendo não apenas a carência de uma sociedade, mas também o resgate da sua memória, através de uma requalificação que reconstrói o passado e ao mesmo tempo traz significação para o presente.

Nesse sentido, o viés histórico e cultural pode ser facilmente interligado e difundido, sendo também palco para o reconhecimento do paisagismo remanescente e extremamente importante, pelo ponto de vista ambiental, por ser parte constituinte da paisagem e pelos benefícios promovidos para o ser humano enquanto área verde.

Vê-se a possibilidade de utilização do espaço através de requalificações com a técnica do retrofit, que promove usos contemporâneos com uma mescla de atividades que evidenciam a atmosfera do espaço e, ao mesmo tempo, transbordam modernidade e tecnologia. Entretanto, ressalta-se que esse contexto partiria de uma parceria público-privada. Vemos exemplos nas Figuras 8 e 9:

Conforme o escritório Mailitis A.I.I.M., a requalificação da antiga cervejaria Cesis Beer, na Letônia, em Centro de Ciências e Artes, teve como base as edificações existentes dos séculos XVIII, XIX e $\mathrm{XX}$, que apresentavam uma rica trama da história industrial da cidade de Cesis. O grande plano foi projetar o terreno transformando em um centro vital de ciência e de artes por meio de uma "arquitetura lenta" - uma abordagem gradual, transformativa para o desenho do espaço público (CROCKETT, 2016).

Já Woods Bagot, apresentou seu projeto de reforma de uma antiga fábrica de açúcar de Hongqi Zhen, no distrito de Jinwan, em Zhuhai. Tal projeto foi previsto para ser executado em três fases e deverá ser concluído daqui a dez anos. O masterplan do local abarca uma área de $80.000 \mathrm{~m}^{2}$, que incluirá vários projetos de revitalização da área que a transformarão em um parque integrado de turismo, cultura e lazer (OVERSTREET, 2018). 


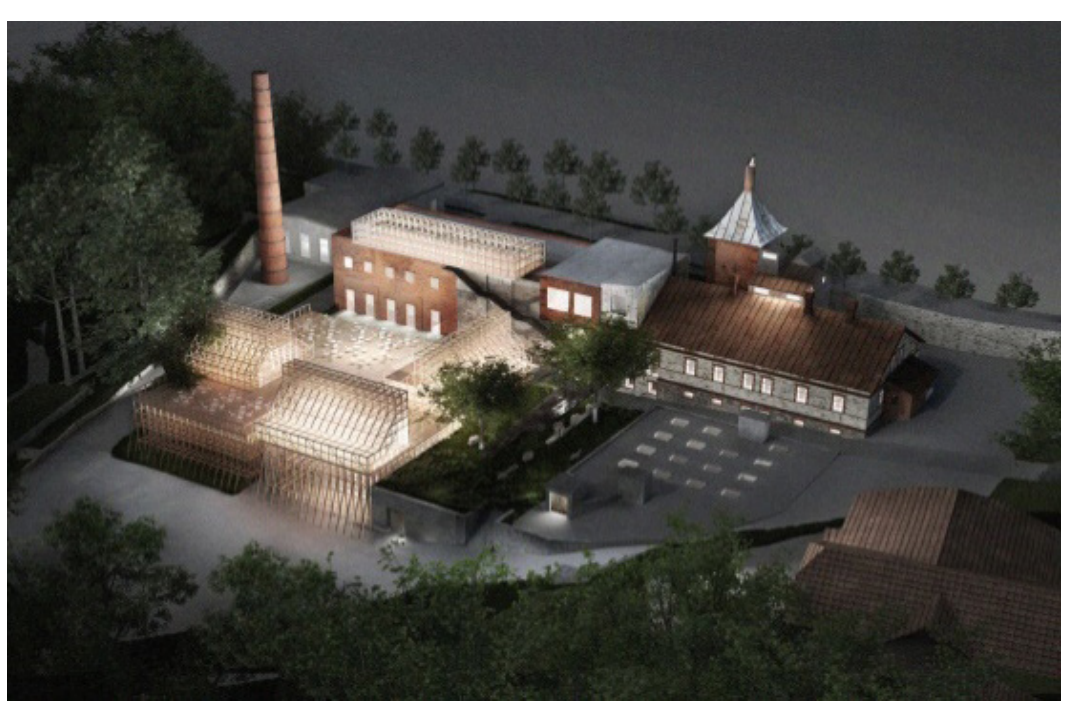

Figura 8 - Projeto de Cesis Brewering.

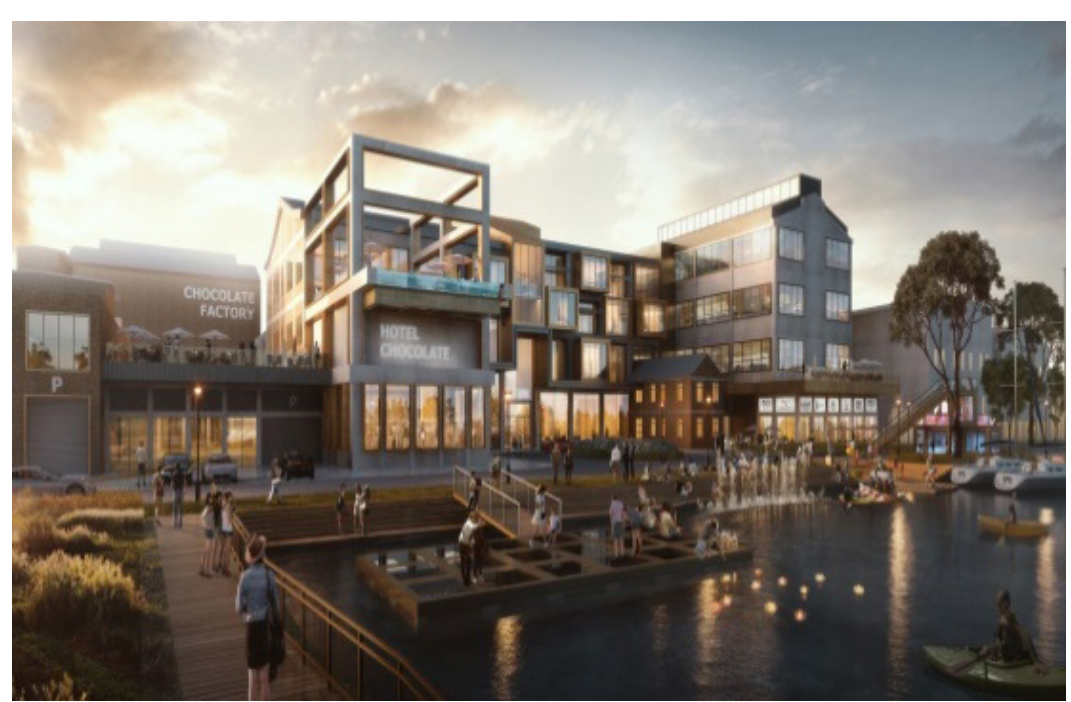

Figura 9 - Projeto de Hongqi Zhen Fonte: Overstreet (2018).

O projeto buscou promover o uso do espaço através de atividades de cunho industrial, cultural e comercial por meio de uma requalificação que englobou todo complexo industrial da usina, bem como todo paisagismo existente. Buscou-se, assim, suprir setores de carência na cidade, promover maior rotatividade turística na região, ser um atrativo com diferencial e valorizar o espaço resgatando a história do lugar.

Segundo o orientador e professor José Luis Maciel Púglia para o $28^{\circ}$ Opera Prima:

destacam-se ainda o uso de materiais na concepção da arquitetura que mantêm as características construtivas originais, não descaracterizando a sua arquitetura industrial, o uso de soluções ambientais também merece destaque como o jardim filtrante para tratamento de efluentes de esgoto, que além de ser uma solução ambientalmente sustentável, valoriza o paisagismo e seu entorno [...]. Sem dúvida, se trata de uma proposta 


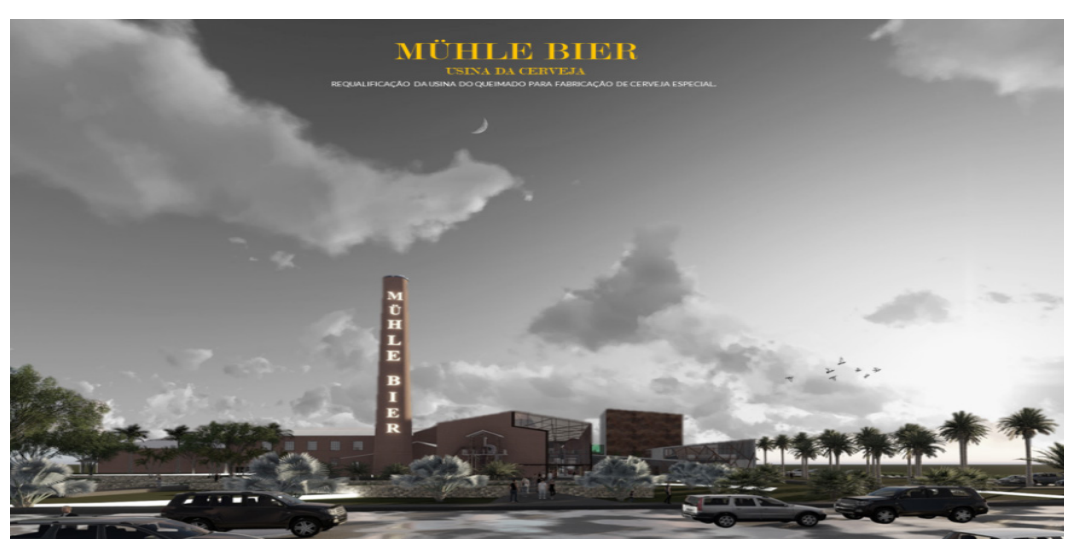

Figura 10 - Projeto de requalificação da Usina do Queimado para fabricação de cerveja especial.

Fonte: Larissa Miranda Sá (2016)

moderna devido ao programa buscar em diferentes áreas a integração e valorização do espaço de modo que não vemos no cotidiano, além disso, resgata a história e preserva o patrimônio da sociedade de Campos dos Goytacazes.

Ao dotar o espaço com novos usos promovendo a integração entre essas atividades, fica em evidência que a solução para requalificação destes espaços requer também novas proposições. Ou seja, estes espaços precisam ser dotados de diferentes atividades, por exemplo, que vão, por exemplo, desde a fabricação da cerveja, visitação na fábrica e antigos maquinários até salas expositivas de arte, coworking lounges e auditórios, pois esta convergência de atividades promove o uso por diferentes usuários, contemplam o resgate destes espaços e sua sustentabilidade.

Contudo, o caráter das intervenções exemplificadas é passível de uma parceria públicoprivada pelo grau de investimento comtemplado nas propostas, pois dificilmente o poder público faria uma intervenção neste grau. Nos casos mencionados acima, por exemplo, poderiam acontecer a partir da aplicação do instrumento Transferência do Direito de Construir. Já para harmonizar com o Direito de Preempção, são passíveis intervenções de natureza social, cultural e ambiental, onde a técnica do retrofit seria utilizada com menor investimento em elementos modernos e tecnológicos.

\section{Considerações Finais}

Este trabalho realizou um estudo acerca da subutilização de complexos industriais e áreas livres remanescentes do período pós-industrial que a cidade de Campos dos Goytacazes experimenta, especialmente sobre o patrimônio da Usina do Queimado localizado à Avenida Dr. Nilo Peçanha, e seu objetivo foi identificar as potencialidades de uso e analisar as suas possibilidades sob o viés político-legal. A motivação desse trabalho está diretamente ligada à sua situação em relação à cidade - localização na malha urbana e potencial arquitetônico e paisagístico.

Desta forma, foi realizada uma abordagem bibliográfica com início na história do objeto de estudo, que se desenvolveu passando por questões de natureza política-legal, econômicas e projetuais. Para tal desenvolvimento, os litígios e a legislação vigente também foram analisados, haja vista a existência de entraves desta natureza no local.

Verificou-se que as possibilidades baseadas na legislação são viáveis, entretanto a ausência de leis municipais específicas corrobora para que os instrumentos não sejam utilizados segundo prerrogativa prevista no Estatuto da Cidade, o que permite a ocorrência de diferentes tipos de intervenções e possibilitam a ação de agentes transformadores do espaço urbano, que mais estão interessados em lucrar com esse tipo de espaço do que, de fato, suprir as carências da cidade.

Fica evidente também que o Plano Diretor do município de Campos dos Goytacazes se apresenta de forma propositiva, quando deveria se apresentar de forma operativa. Ora, se sua função é assegurar que os instrumentos cumpram a função social da propriedade urbana como expressa o Estatuto da Cidade, esse objetivo não está sendo cumprido. 
Dentre os instrumentos, primeiramente destaca-se o Direito de Preempção, por permitir que o poder público tenha preferência na compra do imóvel, e então autonomia para promover intervenções que venham requalificar o espaço trazendo nova significação, abarcando aspectos ambientais, históricos e culturais tão carentes na cidade. Todavia, nos casos de aplicação do referido instrumento, que possibilita uma parceria públicoprivada, apontamos para a Transferência do Direito de Construir, pelo fator de preservação.

Quando observado o instrumento Parcelamento, Edificação e Utilização Compulsórios e complementares, como IPTU Progressivo no Tempo e Desapropriação com Pagamento em Títulos, nota-se que o poder público possui certa tolerância em relação às glebas como as da Usina do Queimado: grandes espaços livres em uma malha urbana há tempo consolidada que não passam pelo crivo do processo de parcelamento, edificação e utilização. Ao analisar esse fato, é possível observar que o Poder Público permite que exista a perda da receita por não aplicar o IPTU Progressivo, agindo assim com improbidade administrativa, além de permitir que o proprietário do imóvel exerça um papel que questiona a função social da propriedade, por exemplo.

No que se refere ao Plano Diretor, faz-se necessário que as leis sejam operativas e que o objetivo maior seja minimizar a desigualdade no espaço urbano e melhorar a qualidade de vida. Essas leis devem ser organizadas por uma equipe multidisciplinar, não se restringindo à vontade política.

Atualmente, o Plano Diretor passa por revisão pelo fato de ter completado dez anos em 2018 e nesse novo plano as intenções são direcionadas para uma construção participativa que poderá trazer novas perspectivas para o espaço em questão.

\section{Referências Bibliográficas}

BRASIL. Lei $\mathrm{n}^{\circ}$ 10.257, de 10 de julho de 2001. Regulamenta os arts. 182 e 183 da Constituição Federal, estabelece diretrizes gerais da política urbana e dá outras providências. Brasília, DF: Presidência da República, 10 jul. 2001. Disponível em: http://www.planalto.gov.br/ccivil_03/ leis/leis_2001//10257.htm. Acesso em: 20 fev. 2019.

CAMPOS DOS GOYTACAZES. Resolução nº 005/2013, de 12 de setembro de 2013. Aprova o tombamento de edificações e móveis e dá outras providências. Diário Oficial do Município de Campos dos Goytacazes, Campos dos Goytacazes, p. 2,12 set. 2013. Disponivel em: https:// www.jusbrasil.com.br/diarios/59095733/dom-goy-rj-13-09-2013-pg-2. Acesso em: 29 jun. 2019. CAMPOS DOS GOYTACAZES. Lei $\mathbf{n}^{\circ} \mathbf{7 . 9 7 4}$, de 31 de março de 2008. Institui a Lei de Uso e Ocupação do Solo Urbano do Município de Campos dos Goytacazes. Campos dos Goytacazes: Prefeitura Municipal, 31 mar. 2008. Disponível em: https://sogi8.sogi.com.br/Arquivo/ Modulo113.MRID109/Registro1262980/lei\%20n\%207.974\%20de\%2031032008.pdf. Acesso em: 19 fev. 2019.

CAMPOS DOS GOYTACAZES. Lei Orgânica do Município de Campos dos Goytacazes/RJ. Diário Oficial do Município de Campos dos Goytacazes, Campos dos Goytacazes, 29 ago. 2014 Disponível em: https://www.campos.rj.gov.br/arquivos/LeiOrganicaDoMunicipio.pdf. Acesso em: 19 fev. 2019.

CAMPOS DOS GOYTACAZES, Lei n 7.972, de 10 de dezembro de 2007. Institui o Plano Diretor do Município de Campos dos Goytacazes. Leis Municipais, [s. I.], dez. 2007. Disponível em https://leismunicipais.com.br/a1/plano-diretor-campos-dos-goytacazes-rj. Acesso em: 19 fev. 2019.

CROCKETT, Lauren. Mailitis A.I.I.M. transforma antiga cervejaria na Letônia em centro de ciências e artes. ArchDaily Brasil, [s. I.], 11 set. 2016. Disponível em: https://www.archdaily. com br/br/795025/mailitis-aiim-transforma-antiga-cervejaria-na-letonia-em-centro-de-ciencom.br/br/795025/mailitis-aiim-trans

FREITAS, Keila Pirovani da Silva. Produção e apropriação do espaço urbano de Campos dos Goytacazes - RJ: da residência unifamiliar aos edifícios de apartamentos. 2011. 166 f. Dissertação (Mestrado em Políticas Sociais) - Universidade Estadual do Norte Fluminense Darcy Ribeiro, Campos dos Goytacazes, Rio de Janeiro, 2011.

GANTOS, Marcelo Carlos; SOUZA FRANCISCO, Quésia. De usinas a usineiros: um ensaio sobre a decadência de uma cultura. In: ENCONTRO REGIONAL DE HISTÓRIA - O HISTORIADOR E SEU TEMPO, 18., 2006, Assis. Anais [...]. Assis: Unesp, 2006. p. 1-12.

HARVEY, David. A produção capitalista do espaço. São Paulo: Annablume, 2005.

MARICATO, Ermínia. Metrópole, legislação e desigualdade. Estudos Avançados, São Paulo, v. 17, n. 48, p. 151-167, jun. 2003.

MESQUITA, Zandor Gomes; TEIXEIRA, Simonne. Usina do queimado: patrimônio industria integrante da paisagem cultural de Campos dos Goytacazes. In: SEMINÁRIO DE PATRIMÔNIO - CULTURA E MEMÓRIA NA FRONTEIRA $n$; COLÓQUIO IBERO-AMERICANO DESAFIOS EPERS- 
em: https://www.academia.edu/6554746/USINA_DO_QUEIMADO_PATRIM\%C3\%94NIO_INDUSTRIAL INTEGRANTE DA PAISAGEM CULTURAL_DE CAMPOS DOS GOYTACAZES. AcesSO em: 03 fev. 2019.

OVERSTREET, Kaley. Woods Bagot transformará antiga fábrica abandonada na China em centro cultural. Archdaily Brasil, [s. I.], 05 jun. 2018. Disponível em: https://www.archdaily. com.br/br/895583/woods-bagot-transformara-antiga-fabrica-abandonada-na-china-em-centro-cultural. Acesso em: 10 mar. 2019.

PINTO, Jorge Renato Pereira. O ciclo do açúcar em Campos. Rio de Janeiro, 1995.

SÁ, Larissa Miranda. Requalificação da Usina do Queimado para fabricação de cerveja artesanal: Mühle Bier. 2016. 186 f. Trabalho Final de Curso (Graduação em Arquitetura e Urbanismo) - Institutos Superiores de Ensino do Censa, Campos dos Goytacazes, 2016.

SABOYA, Renato. Transferência do direito de construir. Urbanidades, Campos dos Goytacazes, 4 ago. 2008. Disponível em: https://urbanidades.arq.br/?p=119. Acesso em 2 jul. 2019.

SANTIN, Janaína Rigo; MARANGON, Elizete Gonçalves. O Estatuto da cidade e os instrumentos de política urbana para proteção do patrimônio histórico: outorga onerosa e transferência do direito de construir. História, São Paulo, v. 27, n. 2, p. 89-109, 2008

\section{Larissa Miranda de Sá}

Instituto Federal Fluminense (IFF), Escola de Arquitetura e Urbanismo

Rua Dr. Siqueira, 273, Parque Dom Bosco, Campos dos Goytacazes, RJ,

Brasil, CEP: 28030-130

Orcid: https://orcid.org/0000-0001-7493-2247

E-mail: Imirandasa@gmail.com

Fagner de Oliveira das Neves

Instituto Federal Fluminense (IFF), Escola de Arquitetura e Urbanismo

Rua Dr. Siqueira, 273, Parque Dom Bosco, Campos dos Goytacazes, RJ,

Brasil, CEP: 28030-130

Orcid: https://orcid.org/0000-0002-3520-2126

E-mail: fagner.oliveira@iff.edu.br

Nota do Editor

Submetido em: 23/05/2019

Aprovado em: 20/09/2019

Revisão do texto: Tikinet 